\title{
LEITURA HERMENÊUTICA DA CARTA DE DIREITOS FUNDAMENTAIS DA UNIÃO EUROPÉIA
}

\author{
Mário Lúcio Quintão Soares*
}

\section{RESUMO}

$\mathrm{O}$ desafio que se coloca às novas fronteiras do constitucionalismo perpassa pela constitucionalização do Direito Internacional em detrimento da concepção hegeliana de ius belium. O constitucionalismo global, emergente da nova ordem internacional, delineia seus traços característicos, mediante a estruturação do sistema jurídico-político no clássico paradigma hobbesiano/westfalliano e no novo paradigma centrado nas relações entre Estado/povo. Verifica-se, portanto, a tendência de elevar-se a dignidade humana a pressuposto básico de todos os constitucionalismos. Neste contexto, o Direito Comunitário tornou-se a argamassa da concretização dos direitos fundamentais, assente na experiência de integração européia. Nesse sentido, há a inserção de catálogo de direitos fundamentais no arcabouço jurídico da União Européia e, especificamente, a compreensão do Tratado da União Européia como uma constituição em sentido material.

Palavras-chaves: Constitucionalização do Direito Internacional. Relações Estado/povo. Direitos Fundamentais e União Européia.

\section{ABSTRACT}

The challenge of the new frontiers of the constitutionalism is a consequence of the internationalization of the Constitucional

* Mestre e doutor em Direito Constitucional pela UFMG; professor de Direito Constitucional e Direito Comunitário dos cursos de mestrado e bacharelado da Faculdade Mineira de Direito da PUC/Minas; diretor da FADIPEL; presidente do Centro de Estudos de Direito Público; presidente da Comissão de Estudos Constitucionais da OAB/MG; Conselheiro Federal da OAB/MG. 
Law in detriment of hegel's conception of ius bellum. The global constitutionalism, that comes from the new international order, delineates its characteristic traces, through the estruturation of the legal-political system in the classic hobbesian/westphalian paradigm centered in the relations between State and people. It verifies, therefore, the tendency to elevate to the human dignity to a basic condition to all constitutionalisms. In this context, the Community Law became the base of the concretion of the fundamental rights, absent in the European experience of integration. In this sense, there is the insertion of a fundamental rights catalogue in the European Union and, specifically, the comprehension of the Treaty on European Union as a constitution in the material sense.

Keywords: Contitucionalization of the International Law. Relations State/people. Fundamental Rights and European Union.

\section{INTRODUÇÃO}

O desafio que se coloca às novas fronteiras do constitucionalismo perpassa pela constitucionalização do Direito Internacional em detrimento da concepção hegeliana de jus ad bellum.

O processo de integração europeu já incorporou catálogo de direitos fundamentais ao seu ordenamento comunitário, não obstante o retrocesso constitucional despertado pelo Tratado de Lisboa, no ocaso de 2007.

Nesse sentido, indaga-se: o que se pretende com a incorporação de uma Carta de Direitos Fundamentais ao arcabouço jurídico comunitário europeu?

O constitucionalismo global, emergente da nova ordem internacional, delineia seus traços característicos, mediante a estruturação do sistema jurídico-político no clássico paradigma hobbesiano/ westfalliano ${ }^{1}$ e no novo paradigma centrado nas relações entre Estado/povo (CANOTILHO, 2006, p. 283 et seq).

Há, ainda, a caracterização do direito ordenamental do Estado pelo pluralismo de ordenamentos superiores, fazendo emergir um ius cogens internacional materialmente informado por valores, princípios e regras universais, gradativamente, plasmados em declarações e documentos internacionais. ${ }^{2}$ 
Verifica-se, portanto, "a tendência de elevar-se a dignidade humana a pressuposto básico de todos os constitucionalismos" (CANOTILHO, 1998, p. 1218).

Entretanto, o poder constituinte dos Estados, formalizado nas constituições nacionais, tende a atrelar-se aos princípios e às regras de Direito Internacional peremptório. Este, por sua vez, carrega consigo o propósito da sua transformação, em parâmetro de validade das constituições nacionais cujas normas devem ser consideradas nulas, caso violem as normas do ius cogens internacional.

Há, evidentemente, a contraposição entre os constitucionalismos global enacional, tornando imperiosa a necessidade de secompreender a experiência européia comunitária como uma superação dos quadros tradicionais dominantes no constitucionalismo. ${ }^{3}$

Nesse sentido, implica admitir a existência de uma constituição européia, ora material, fora do quadro estatal, com exigências específicas para um processo de integração, compatível com a existência de outras constituições no âmbito dos Estados-membros.

Da coexistência destes vários planos constitucionais evitase a tensão entre o todo e suas partes componentes, pois o Direito Comunitário e o Direito Constitucional interno, restrito às fronteiras de cada Estado, se complementam e podem vigorar, simultaneamente, no espaço comunitário europeu (SOARES, 2000, 2008). ${ }^{4}$

Percebe-se, então, em decorrência desta harmonização legislativa, um processo de constitucionalização dos tratados comunitários, mediante leitura hermenêutica adequada, desenvolvida pelo Tribunal de Justiça da União Européia (TJ), tendo como pano de fundo a proteção dos direitos fundamentais do cidadão europeu.

Assim, o Direito Comunitário tornou-se a argamassa da concretização dos direitos fundamentais, assente na experiência de integração européia, construída desde a década de 50, observando-se:

a) Os valores comuns consagrados nas ordens jurídicas comunitárias e estatais;

b) a doutrina comunitária;

c) a tentativa de colmatar a lacuna jurídica em relação aos direitos fundamentais no âmbito comunitário, através da jurisprudência do TJ; d) a inserção de catálogo de direitos fundamentais nos tratados comunitários europeus; 
e) e, especificamente, a compreensão do Tratado da União Européia como uma constituição em sentido material (GUERRA MARTINS, 2004, p. 139 et seq).

\section{A RECEPÇÃO DO CATÁLOGO DE DIREITOS FUNDA- MENTAIS PELOS TRATADOS COMUNITÁRIOS}

Dada a ausência deste catálogo, no decorrer do processo histórico da construção das Comunidades, a proteção aos direitos fundamentais, constitucionalizados nos tratados comunitários, emergiu da interpretação de seus princípios e regras pelo TJ.

Entretanto, houve uma transmutação ideológica na evolução dos tratados comunitários, o que ensejou uma constituição transnacional em sentido material, manifesta na proclamação da Carta de Direitos Fundamentais da UE, em Nice, em 7/12/2000.

Esta Constituição materializou-se, devido ao caráter dinâmico e evolutivo do processo de integração europeu, ao haurir as tradições constitucionais comuns e peculiares aos Estados integrantes da União Européia.

A Carta de Direitos Fundamentais, aprovada em Nice, mesmo sem caráter vinculativo, corresponde a uma autêntica Declaração de Direitos desta Constituição material, tendo como fontes:

a) a Convenção Européia dos Direitos do Homem;

b) os próprios tratados instituidores da $\mathrm{EU}^{6}$;

c) a Carta Social Européia de 19617;

d) a Carta Comunitária de Direitos Sociais Fundamentais dos Trabalhadores de $1989^{\circ}$.

E, como tal, adota regras clássicas de proteção aos cidadãos comuns contra abusos de eventuais detentores de poder.

Seu próprio preâmbulo assinala seus propósitos:

a) na referência, no seu art. $1^{\circ}$, aos povos da Europa, em detrimento das Altas partes contratantes, propiciando maior legitimidade à Carta;

b) na assertiva de que a União Européia coloca o cidadão europeu no cerne de suas ações;

c) no compromisso de que as pessoas individualmente consideradas, a comunidade humana e as gerações futuras devem assumir responsabilidades e deveres, conforme os direitos enunciados na Carta. 
Verifica-se, portanto, que a Carta, em busca da segurança jurídica, não pretende criar novos direitos, mas tornar visíveis os existentes e que integram o patrimônio comum dos cidadãos europeus (CRAIG, 2002, p. 221 et seq).

\section{A CARTA DOS DIREITOS FUNDAMENTAIS DA UNIÃO EUROPÉIA EM SI}

Esta Carta foi assinada e proclamada pelos presidentes do Parlamento Europeu, do Conselho Europeu e da Comissão Européia, por ocasião do Conselho Europeu de Nice, em 7 de Dezembro de 2000.

Trata-se de um catálogo de direitos fundamentais, com o intuito de retomar, num texto único, o conjunto de direitos cívicos, políticos, econômicos e sociais dos cidadãos europeus, assim como de todas as pessoas domiciliadas no território da União.

Tais direitos baseiam-se, essencialmente, nos direitos e liberdades fundamentais reconhecidos na Convenção Européia dos Direitos do Homem, nas tradições constitucionais dos Estados-membros da União Européia e em outras convenções internacionais subscritas pela União ou pelos seus Estados.

O capítulo primeiro desta Carta refere-se à dignidade do ser humano, que é inviolável e deve ser respeitada e protegida.

A Carta preconiza no tocante à inviolabilidade da dignidade do ser humano( $\left.\operatorname{art} .1^{\circ}\right)$ :

- o direito à vida $\left(\operatorname{art} .2^{\circ}\right) ;{ }^{9}$

- à integridade física $\left(\operatorname{art} .3^{\circ}\right)$;

- a proibição da tortura e dos tratos ou penas desumanas ou degradantes( $\left.\operatorname{art} .4^{\circ}\right)$;

- a proibição da escravatura e do trabalho forçado(art. $\left.5^{\circ}\right) . .^{10}$

Será que há respeito à dignidade humana para as minorias étnicas que se encontram no âmbito da União Européia?

Dentre as minorias étnicas podem ser inseridos nacionais, não nacionais, porém residentes ou mesmo não documentados, com problemas específicos (JUAREZ PÉREZ, 1998, p. 184 et seq.). 
Os não-documentados, dado o fato de estarem em situação ilegal, vêem-se privados de direitos básicos de cidadania, tais como o de exigir o cumprimento de contratos de trabalho que realizem com entidades patronais, ou de acesso ao sistema de saúde (salvo para as crianças) e de segurança social.

A precariedade da sua situação implica o desenvolvimento de máfias internacionais de tráfico de pessoas, principalmente para as teias sedutoras da prostituição. Aos próprios residentes são ainda negados direitos políticos fundamentais, em decorrência de não usufruírem da nacionalidade, demarcada pelo ius sanguinis.

Á exceção dos cidadãos comunitários em relação às eleições autárquicas e européias, os cidadãos residentes, destituídos do necessário status de nacionalidade, permanecem excluídos dos processos decisórios dos Estados democráticos, integrantes da União Européia.

Nesse sentido, a comunidade turca reivindica junto ao governo alemão a modificação de sua política de integração. Uma quota de empregos seria um primeiro passo nesta direção.

A meta da minoria turca, estrategicamente, consiste em conquistar o direito de votar nas eleições municipais, além de poder preservar a cidadania original, mesmo se naturalizando como alemães.

O capítulo segundo refere-se às liberdades em si, ao abranger direitos tão díspares, tais como:

- à liberdade e à segurança (art. $\left.6^{\circ}\right)$;

- à vida privada e familiar (art. $\left.7^{\circ}\right)$;

- à proteção de dados pessoais $\left(\operatorname{art} .8^{\circ}\right)$;

- de contrair casamento e de constituir família (art.9);

- à liberdade de pensamento, de consciência e religião(art.10 ${ }^{\circ}$;

- à liberdade de expressão e de informação (art.11º);

- à liberdade de reunião e de associação(art.12 ${ }^{\circ}$;

- à liberdade das artes e das ciências $\left(\operatorname{art} .13^{\circ}\right)$;

- à educação(art.14\%);

- à liberdade profissional e o direito ao trabalho(art.15 $)$;

- à liberdade de empresa $\left(\operatorname{art} .16^{\circ}\right)$;

- de propriedade $\left(\operatorname{art} .17^{\circ}\right)$;

- de asilo (art.18 $)$;

- à proteção em caso de afastamento, expulsão ou extradição $\left(\operatorname{art} .19^{\circ}\right)$. 
O capítulo terceiro embrenha-se nas sinuosas veredas da igualdade, ao enfatizar o significado desse princípio perante a lei $\left(\operatorname{art} .20^{\circ}\right)$. Em seguida, seu conteúdo encaminha-se para o princípio da não discriminação $\left(\operatorname{art} .21^{\circ}\right)$, o respeito da diversidade cultural, religiosa e lingüística $\left(\operatorname{art} .22^{\circ}\right)$, a igualdade entre homens e mulheres $\left(\operatorname{art} .23^{\circ}\right)$, os direitos das crianças $\left(\right.$ art. $\left.24^{\circ}\right)$, os direitos das pessoas idosas $\left(\operatorname{art} .25^{\circ}\right)$ e a integração das pessoas com deficiência (art.26 $)$.

A diversidade religiosa que caracteriza a Europa demonstra, estatisticamente, uma hipotética região sul mais católica, outra região norte com tendência protestante e até uma oriental, ortodoxa e muçulmana.

Se uma porção significativa da população da UE se declara católica, há Estados-membros em que a população religiosa é quase integralmente protestante (Dinamarca e Suécia) ou ortodoxa (Grécia).

Para além dos cristãos, habitam na União Européia milhões de muçulmanos (França e Alemanha, por exemplo).

Na Grã-Bretanha, existe ainda considerável comunidade de hindus e sikhs, dentre outros.

O capítulo quarto, ao procurar regular a solidariedade11, inclui os seguintes direitos:

- à informação e à consulta dos trabalhadores na empresa (art.27),

- à negociação e de ação coletiva $\left(\operatorname{art} .28^{\circ}\right)$,

- de acesso ao emprego (art.29\%),

- a proteção em caso de despedida sem justa causa $\left(\operatorname{art} .30^{\circ}\right)$,

- as condições de trabalho justas e eqüitativas $\left(\operatorname{art} .31^{\circ}\right.$ ),

- à proibição do trabalho infantil e proteção em caso de despedida sem justa causa $\left(\operatorname{art} .30^{\circ}\right)$,

- às condições de trabalho justas e eqüitativas $\left(\operatorname{art.} 31^{\circ}\right)$,

- à proibição do trabalho infantil e proteção da vida familiar e vida profissional $\left(\operatorname{art} .33^{\circ}\right)$,

- à segurança social e à assistência social $\left(\operatorname{art} .34^{\circ}\right)$,

- à proteção à saúde $\left(\operatorname{art} .35^{\circ}\right)$,

- ao acesso aos serviços de interesse econômico $\left(\operatorname{art.36} 6^{\circ}\right)$,

- à proteção do meio ambiente (art. $\left.37^{\circ}\right)$

- à defesa dos direitos do consumidor $\left(\operatorname{art} .38^{\circ}\right)$.

No entanto, os imigrantes e as minorias étnicas continuam a enfrentar grandes dificuldades no acesso aos serviços de saúde 
europeus, em especial no tratamento e prevenção da Aids, segundo a European Aids Treatment Group (EATG).

Um dos grandes objetivos da União Européia, em termos de solidariedade e de direito à vida, consiste em garantir o acesso, a todas as pessoas residentes em seu espaço comunitário, a tratamentos de saúde, o que inclui, necessariamente, também os imigrantes e as minorias étnicas.

A lacuna existente tem de ser resolvida, pois é inadmissível a exclusão de certos grupos ou comunidades em relação ao direito à saúde, por não terem documentação, por falta de informação nas suas línguas ou, simplesmente, porque são lamentavelmente discriminados.

O conteúdo da Carta, muito abrangente, deve ser considerado standard mínimo, ao preconizar os direitos fundamentais imprescindíveis ao exercício da cidadania na União Européia.

\section{REFERENNCIAS}

BAPTISTA, Eduardo Correia. Ius cogens em direito internacional. Lisboa: Lex, 1997.

CANOTILHO, J. J. Gomes. Brancosos e internconstitucionalidade: itinerários sobre a historicidade constitucional. Coimbra: Almedina, 2006.

. Direito constitucional e teoria da constituição. 2. ed. Coimbra: Almedina, 1998.

CRAIG, P. The Community rights and the Charter. ERPL/REDP, 2002.

DRUESNE, Gérard - 8ème éd. mise à. jour. - Paris: Presses Universitaires de France, D.L. 2006.

GUERRA MARTINS, Ana Maria. Curso de direito constitucional da união européia. Coimbra: Almedina, 2004.

JUAREZ PEREZ, Pilar. Nacionalidad estatal y ciudadania europea. Madrid: Marcial Pons, 1998. 
LECOURT, Benoit. L' influence du droit communautaire sur la constitution de groupements. Paris: LGDJ, 2000.

SOARES, Mário Lúcio Quintão. Direitos fundamentais e direito comunitário. Belo Horizonte: Del Rey, 2000.

Teoria do Estado: novos paradigmas em face da globalização. 3. ed. São Paulo: Atlas, 2008.

\section{NOTAS}

1 Relações horizontais entre Estados na tradição ocidental.

2 Porém, o conceito de ius cogens permanece ambíguo, apesar de incluir o direito à autodeterminação como direito fundamental da democracia, bem como, no âmbito das liberdades pessoais, um mínimo de proteção à vida, à liberdade e à segurança da liberdade. Vide nesse sentido BAPTISTA, Eduardo Correia. Ius cogens em direito internacional. Lisboa: Lex, 1997.

3 Sobre sua repercussão no Direito privado, vide LECOURT, Benoit. L' influence du droit communautaire sur la constitution de groupements. Paris: LGDJ, 2000.

4 Vide, nesse sentido, minha obras Direitos Fundamentais e direito comunitário. Belo Horizonte: Del Rey, 2000 e Teoria do Estado: novos paradigmas em face da globalização. 3. ed. São Paulo: Atlas, 2008.

5 Relativa aos direitos civis e políticos. Esta convenção ampliou o leque dos direitos protegidos e otimizou seu sistema de garantias.

6 Em matéria de direitos do cidadão europeu.

7 Em relação aos direitos sociais, com aplicação assimétrica pelos Estados partes.

8 Que não possui valor vinculativo.

9 Todas as pessoas têm direito à vida. Ninguém pode ser condenado à pena de morte, nem executado. Na Europa Ocidental, a pena capital está extinta. Por exemplo, a França a extinguiu, por força da. Lei n. 81.908, de 9-10-1981, art. $1^{\circ}$.

10 Direitos reconhecidos na CEDH e em outros instrumentos internacionais(vide Pacto de Direitos Civis e Políticos das Nações Unidas), possuindo um amplo consenso.

11 Vide, nesse sentido, sobre a liberdade de circulação de pessoas, DRUESNE, Gérard

- 8ème éd. mise à. jour. - Paris: Presses Universitaires de France, D.L. 2006.

Artigo recebido em: 02/05/2008

Aprovado em: 26/06/2008 